\section{6 OPEN ACCESS}

\title{
Efficacy and safety of mavrilimumab in subjects with rheumatoid arthritis
}

\author{
Gerd R Burmester, ${ }^{1}$ Michael E Weinblatt, ${ }^{2}$ lain B McInnes, ${ }^{3}$ Duncan Porter, ${ }^{4}$ \\ Olga Barbarash, ${ }^{5}$ Mykola Vatutin, ${ }^{6}$ Istvan Szombati, Ehsanollah Esfandiari, ${ }^{8}, 12$ \\ Matthew A Sleeman, ${ }^{8}$ Christopher D Kane ${ }^{9,15}$ Guy Cavet, ${ }^{10,14}$ Bing Wang, ${ }^{11}$ \\ Alex Godwood, ${ }^{8}$ Fabio Magrini, ${ }^{8,13}$ for the EARTH Study Group
}

\begin{abstract}
Handling editor Tore K Kvien
Additional supplementary files are published online only. To view these files please visit the journal online (http://dx.doi. org/10.1136/annrheumdis-

2012-202450).
\end{abstract}

For numbered affiliations see end of article.

\section{Correspondence to}

Dr Gerd R Burmester,

Charité-University Medicine

Berlin, Free University and

Humboldt University Berlin,

Charitéplatz 1, Berlin 10117,

Germany;

Gerd.Burmester@charite.de

Accepted 20 October 2012

Published Online First

12 December 2012

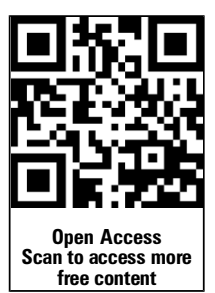

\section{S Linked}

http://dx.doi.org/10.1136/ annrheumdis-2012-202275

- http://dx.doi.org/10.1136/ annrheumdis-2012-202775

- http://dx.doi.org/10.1136/ annrheumdis-2012-202864

- http://dx.doi.org/10.1136/ annrheumdis-2013-203261

\section{ABSTRACT}

Objectives Mavrilimumab, a human monoclonal antibody targeting the alpha subunit of the granulocytemacrophage colony-stimulating factor receptor, was evaluated in a phase 2 randomised, double-blind, placebo-controlled study to investigate efficacy and safety in subjects with rheumatoid arthritis (RA).

Methods Subcutaneous mavrilimumab $10 \mathrm{mg}, 30 \mathrm{mg}$, $50 \mathrm{mg}$, or $100 \mathrm{mg}$ ) or placebo was administered every other week for 12 weeks in subjects on stable background methotrexate therapy. The primary endpoint was the proportion of subjects achieving a $\geq 1.2$ decrease from baseline in Disease Activity Score (DAS28-CRP) at week 12

Results $55.7 \%$ of mavrilimumab-treated subjects met the primary endpoint versus $34.7 \%$ placebo $(p=0.003)$ at week 12; for the $10 \mathrm{mg}, 30 \mathrm{mg}, 50 \mathrm{mg}$, and $100 \mathrm{mg}$ groups, responses were $41.0 \%(p=0.543), 61.0 \%$ $(p=0.011), 53.8 \%(p=0.071)$, and $66.7 \%(p=0.001)$ respectively. Response rate differences from placebo were observed at week 2 and increased throughout the treatment period. The $100 \mathrm{mg}$ dose demonstrated a significant effect versus placebo on DAS28-CRP $<2.6$ $(23.1 \%$ vs $6.7 \%, p=0.016)$, all categories of the American College of Rheumatology (ACR) criteria (ACR20: $69.2 \%$ vs $40.0 \%, p=0.005$; ACR50: $30.8 \%$ vs $12.0 \%, p=0.021$; ACR70: $17.9 \%$ vs $4.0 \%, p=0.030$ ), and the Health Assessment Questionnaire Disability Index $(-0.48$ vs $-0.25, p=0.005)$. A biomarker-based disease activity score showed a dose-dependent decrease at week 12 , indicating suppression of disease-related biological pathways. Adverse events were generally mild or moderate in intensity. No significant hypersensitivity reactions, serious or opportunistic infections, or changes in pulmonary parameters were observed.

Conclusions Mavrilimumab induced rapid clinically significant responses in RA subjects, suggesting that inhibiting the mononuclear phagocyte pathway may provide a novel therapeutic approach for RA.

The Corresponding Author has the right to grant on behalf of all authors and does grant on behalf of all authors, an exclusive licence (or non exclusive for government employees) on a worldwide basis to the BMJ Publishing Group Ltd to permit this article (if accepted) to be published in ARD and any other BMJPGL products and sublicences such use and exploit all subsidiary rights, as set out in our license.

\section{INTRODUCTION}

Despite the many treatments introduced for rheumatoid arthritis (RA), significant proportions of patients fail to achieve meaningful responses and are not adequately controlled. ${ }^{1}$ New therapies with novel mechanisms of action are still needed to address this unmet need. We postulate that direct modulation of macrophage function via granulocyte-macrophage colony-stimulating factor receptor (GM-CSFR) inhibition may provide a treatment option in RA. GM-CSF may play a central role in the pathogenesis of RA through the activation, differentiation and survival of neutrophils and macrophages. ${ }^{2}$ Macrophages promote synovitis via release of cytokines, chemokines, reactive oxygen and nitrogen intermediates, proteases and microparticles. The number of macrophages in synovial tissue is correlated with radiographic progression; ${ }^{3}$ reductions in CD68+ macrophages correlate with improvement in disease activity scores. ${ }^{4-6}$ RA patients exhibit increased GM-CSF levels in synovial fluid, plasma and synoviocytes, ${ }^{7-9}$ and recombinant GM-CSF has been reported to exacerbate disease in those patients. ${ }^{10-12}$

Mavrilimumab (CAM-3001) is a fully-human monoclonal antibody targeting the alpha subunit of GM-CSFR. In a phase 1 single ascending intravenous dose study in 32 subjects with RA, mavrilimumab showed a safety and tolerability profile supporting clinical development, and biological activity on acute phase reactants. ${ }^{13}$ This phase 2 a study evaluated the efficacy and safety of subcutaneous (SC) mavrilimumab in subjects with moderate-to-severe active RA. This is the first study to investigate macrophage inhibition through direct blockage of GM-CSFR $\alpha$ as a novel therapeutic approach in RA.

\section{METHODS}

\section{Study design}

This multicentre, randomised, double-blind, placebo-controlled study (EARTH Study; NCT01050998) evaluated the efficacy, safety and tolerability profile of ascending SC mavrilimumab doses in combination with stable methotrexate in subjects with moderate-to-severe active RA. Subjects were randomised between February 2010 
and March 2011 at 53 centres across 10 Eastern European countries.

Subjects were randomised using an interactive voice response system in a 2:1 ratio (active:placebo) within each cohort and received, either $10,30,50$, or $100 \mathrm{mg}$ SC doses of mavrilimumab or placebo every other week for 12 weeks, followed by a 12-week follow-up period.

Doses and administration frequency were based on phase 1 data ${ }^{13}$ and pharmacokinetic-pharmacodynamic modelling. ${ }^{14}$ For Cohorts 1-3, dose escalation to the next cohort was based on a cumulative safety data review after $\geq 18$ subjects completed day 29 dosing; for Cohort 4, six subjects received mavrilimumab $100 \mathrm{mg}$ for the entire treatment period (12 weeks) and based on the safety review, randomisation was resumed.

Background stable non-steroidal anti-inflammatory drugs and oral corticosteroids ( $\leq 10 \mathrm{mg} /$ day prednisolone or equivalent) were allowed.

The study was conducted in accordance with the principles of the Declaration of Helsinki and the International Conference on Harmonisation Guidance for Good Clinical Practice. Independent ethics committee approval was obtained. All subjects provided written informed consent. The protocol was jointly developed by the academic authors and the sponsor, MedImmune, who collected the data. Authors had full access to data and certify the veracity and completeness of the data and the data analysis.

\section{Subjects}

Subjects were 18-80 years with at least moderately active (Disease Activity Score (DAS)28-CRP $\geq 3.2)^{15}$ adult-onset RA of $\geq 3$ months duration, ${ }^{16}$ despite methotrexate (7.5-25 mg/week) treatment for $\geq 12$ weeks, and positive for anti-cyclic citrullinated peptide antibody (ACPA, $>5 \mathrm{IU} / \mathrm{ml}$; Axis Shield by ELISA) and/or rheumatoid factor (>14 IU/ml; Tina-Quant, Roche Diagnostics, Indianapolis, Indiana, USA and ELISA, Immco Diagnostics, Buffalo, New York, USA). All subjects received stable methotrexate (for $\geq 4$ weeks) with supplemental folic acid $\geq 5 \mathrm{mg} /$ week. Subjects previously treated with 1 biologic therapy for RA but discontinued for lack of efficacy were eligible for entry in the study. Subjects with symptomatic or uncontrolled lung disease, active infection, or at a high risk of infection were excluded.

\section{Efficacy assessments}

Efficacy assessments were performed at baseline and every 2 weeks during the 12 -week treatment period and at 2 weeks, 1 month, and 3 months after the last dose. The primary endpoint was defined as the proportion of subjects achieving a reduction of $\geq 1.2$ points from baseline in DAS28-CRP ${ }^{17}$ at week 12 .

Secondary endpoints included time to onset of response and DAS28-CRP $<2.6$, improvements to the Health Assessment Questionnaire Disability Index (HAO-DI $)^{18}$ score, European League Against Rheumatism (EULAR), and American College of Rheumatology (ACR) response criteria.

\section{Biomarker assessment}

Twelve biomarkers (c-reactive protein (CRP), epidermal growth factor (EGF), Leptin, IL-6, MMP-1, MMP-3, Resistin, SAA, TNFR-I, VCAM-1, VEGF-A, YKL-40) were measured in serum samples from baseline and day 88 (Meso Scale Discovery MULTI-ARRAY platform). A multi-biomarker disease activity (MBDA) score was calculated for each sample by combining the concentrations of these biomarkers in the Vectra DA algorithm. The algorithm was trained and validated in previous studies using DAS28-CRP as a reference measure. ${ }^{19-21}$

\section{Safety and tolerability assessments}

Respiratory monitoring (chest $\mathrm{x}$-ray, forced expiratory volume $\left(F_{1}\right)$, forced vital capacity (FVC), diffusing capacity of the lung for carbon monoxide (DLCO), and dyspnoea score) was performed at baseline and throughout the study because GM-CSF inhibition could affect alveolar macrophage function and surfactant homeostasis in the lung. ${ }^{22} 23$ The protocol mandated treatment discontinuation if pulmonary function deteriorated by $>20 \%$ of baseline spirometry or DLCO values and for the changes to be reported as adverse events (AEs).

Serum surfactant D (SP-D) and KL-6 levels (ELISA; Sanko Junyaku Co, Japan)—established biomarkers for lung damage ${ }^{24-27}$ - were measured at baseline and on days 29, 85, and 169. Other safety assessments included the incidence of AEs and serious AEs (SAEs) and routine laboratory testing.

\section{Pharmacokinetics and immunogenicity}

Serum mavrilimumab concentrations were measured from blood samples collected at the first and last doses, and at pre-designated timepoints using a validated electrochemiluminescence assay. The presence of anti-drug antibodies (ADA) was determined using a two-step approach: an electrochemiluminescence screening immunoassay and a confirmatory inhibition assay.

\section{Statistical methods}

Sample size calculations were based on the primary endpoint at week 12 . We assumed a placebo response rate of $10 \%$, a $15 \%$ drop-out rate, and used a two-sided significance level of 0.05 , and a 2:1 (active:placebo) randomisation ratio. The total sample size of 216 subjects provided $86 \%$ power to detect a $20 \%$ difference in response rate between the combined mavrilimumab arms and placebo using Fisher's exact test. All response rates, including the primary endpoint, ACR20, ACR50, and ACR70, were analysed using Fisher's exact test. Changes from baseline in DAS28-CRP and HAQ-DI were analysed using a mixed-model repeated measures analysis with a covariate for baseline DAS28-CRP. The time-to-onset of response was analysed using a log-rank test.

All efficacy analyses were conducted on the intent-to-treat (ITT) population (all subjects randomised, regardless of whether they received treatment). Each analysis was conducted to compare the combined placebo and combined mavrilimumab groups, followed by comparison of the combined placebo group with each of the mavrilimumab dose cohorts. Analysis of safety data was carried out on the safety population (all subjects who received any dose of study medication).

For the primary endpoint as well as the other responder analyses, a non-responder imputation was used for subjects who withdrew from study treatment, changed the dose of background methotrexate, or received other RA medication. Other missing data points were imputed using last-observation-carried-forward methodology. No imputation was applied for the DAS28-CRP change from baseline analysis. Noncompartmental analysis was performed on individual pharmacokinetic (PK) data for the first and last doses. Biomarker data were analysed by Mann-Whitney $\mathrm{U}$ test and linear regression. Significance for individual biomarkers was evaluated by false discovery rate. ${ }^{28}$

\section{RESULTS}

Of 427 subjects screened, 239 were subsequently randomised into the four cohorts. Of these, 233 were included in the ITT 


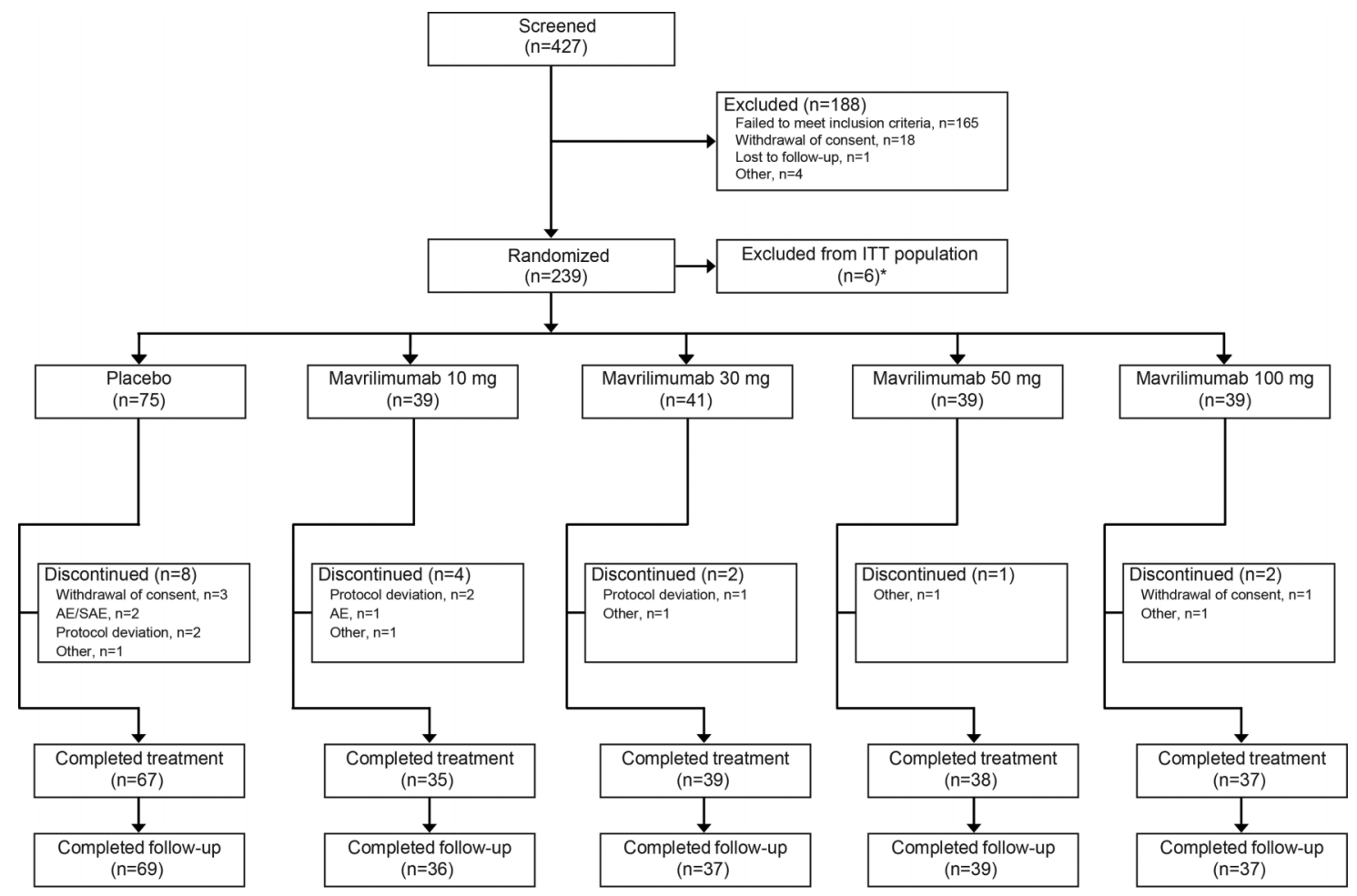

*Site excluded due to data integrity issues

Figure 1 Patient disposition (ITT population).

population, 216 completed the study, and 17 discontinued, three of which were due to AEs (figure 1). The treatment groups were generally balanced in terms of baseline and disease characteristics (table 1); the $50 \mathrm{mg}$ group had a slightly higher proportion of female subjects and a lower mean dose of methotrexate.

\section{Efficacy}

Administration of mavrilimumab (all doses combined, $n=158$ ) was associated with a significantly higher proportion of subjects achieving a $\geq 1.2$-point reduction in DAS28-CRP than placebo $(n=75)$ at week $12(55.7 \%$ vs $34.7 \%$; $p=0.003)$ (figure 2A). A significant difference in DAS28-CRP adjusted mean change from baseline compared with placebo was seen for the $50 \mathrm{mg}(-0.38,95 \% \mathrm{CI}-0.67$ to $-0.08 ; \mathrm{p}=0.013)$ and $100 \mathrm{mg}(-0.44,95 \% \mathrm{CI}-0.74$ to $-0.14 ; \mathrm{p}=0.004)$ cohorts as early as week 2 (figure $2 \mathrm{~B}$ ). DAS28-CRP $<2.6$ rates increased over time in all treated groups; the $100 \mathrm{mg}$ dose demonstrated a significant effect $(23.1 \%$ vs $6.7 \%$; $=0.016)$ by week 12 and the number of subjects achieving DAS28-CRP $<2.6$ was still increasing at week 12 (figure $2 \mathrm{~A}-\mathrm{C}$ ).

At the $100 \mathrm{mg}$ dose, significant improvement in HAQ-DI versus placebo was observed from week 6 ( -0.36 vs -0.19 ; $\mathrm{p}=0.041)$ through week 12 ( -0.48 vs $-0.25 ; p=0.005$; figure 2D), with $74.4 \%$ mavrilimumab vs $48.0 \%$ placebo subjects reporting clinically significant improvements $(\geq 0.25 ; p=0.009)$. The adjusted mean differences $(95 \% \mathrm{CI})$ from baseline versus placebo were $-0.17(-0.33,-0.01)$ and $-0.23(-0.39,-0.07)$.

The largest treatment effect, as assessed by ACR criteria, was seen in the $100 \mathrm{mg}$ dose at week 12 vs placebo (ACR20 69.2 vs $40.0 \%, p=0.005 ;$ ACR50 30.8 vs $12.0 \%, p=0.021 ;$ ACR70 17.9 vs $4.0 \%, p=0.030$ ) (figure $3 \mathrm{~A}$ ) with a significant separation from placebo seen as early as week 4 (ACR20 53.8\% vs $20.0 \%$ $\mathrm{p}<0.001$ ) (figure $3 \mathrm{~B}-\mathrm{D}$ ). A larger proportion of subjects receiving mavrilimumab showed a moderate or good EULAR response versus placebo ( 67.7 vs $50.7 \%$; $p=0.025)$. The highest proportion of moderate $(46.2 \%)$ or good responders $(30.8 \%)$ was seen in the $100 \mathrm{mg}$ group.

Significant changes were seen from week 2 in CRP $(p=0.004)$ and erythrocyte sedimentation rate $(E S R)(p=0.005)$ in the mavrilimumab groups versus placebo, and in swollen and tender joint count from week $4(p=0.002$ and $p=0.011$, respectively) (see web only files).

Efficacy observed in the $100 \mathrm{mg}$ group at week 12 was maintained through the follow-up to week 24 , manifested both as a $\geq 1.2$-point reduction in DAS28-CRP (59.0\% vs $33.3 \%$ placebo; $\mathrm{p}=0.010)$ and ACR20 response $(56.4 \%$ vs $30.7 \%$ placebo; $\mathrm{p}=0.009)$. This 'post-treatment' maintenance of response was not observed for DAS28-CRP<2.6, ACR50, and ACR70 (figures $2 \mathrm{C}$ and $3 \mathrm{C}, \mathrm{D}$ ).

Ninety-one per cent of subjects in the ITT population had sufficient sample available for biomarker analyses (placebo ( $n=65)$; mavrilimumab ( $n=146): 10 \mathrm{mg}(\mathrm{n}=35), 30 \mathrm{mg}(\mathrm{n}=37)$, $50 \mathrm{mg}(\mathrm{n}=38)$, and $100 \mathrm{mg}(\mathrm{n}=36))$. At baseline, MBDA scores reflected the severe disease activity measured by DAS28-CRP. The MBDA score decreased more in the combined mavrilimumab-treated subjects versus placebo at week 12 $(p=0.008)$ and decreases were dose-dependent $(p<0.001)$ (figure 2E). There were also dose-dependent decreases in the constituent biomarkers CRP, IL-6, MMP-3, SAA, and YKL-40 (false discovery rate $<0.05$ ) (see web only files). Significant reductions in markers of systemic inflammation (CRP, SAA, IL-6) were observed within 1 month, with significant changes in YKL40 and MMP3 not being observed until week 12.

\section{Safety and tolerability}

Over the 24-week study period, 36 (45.6\%) subjects receiving placebo and 91 (56.9\%) receiving mavrilimumab experienced an AE (table 2). 
Table 1 Baseline and disease characteristics (Intent-to-treat population)

\begin{tabular}{|c|c|c|c|c|c|c|}
\hline & \multirow[b]{2}{*}{ Placebo $(n=75)$} & \multicolumn{5}{|l|}{ Mavrilimumab } \\
\hline & & $10 \mathrm{mg}(\mathrm{n}=39)$ & $30 \mathrm{mg}(\mathrm{n}=41)$ & $50 \mathrm{mg}(\mathrm{n}=39)$ & $100 \mathrm{mg}(\mathrm{n}=39)$ & Total $(n=158)$ \\
\hline \multicolumn{7}{|l|}{ Demography } \\
\hline \multicolumn{7}{|l|}{ Gender, n (\%) } \\
\hline Male & $9(12.0)$ & $7(17.9)$ & $5(12.2)$ & $2(5.1)$ & $5(12.8)$ & $19(12.0)$ \\
\hline Female & $66(88.0)$ & $32(82.1)$ & $36(87.8)$ & 37 (94.9) & $34(87.2)$ & $139(88.0)$ \\
\hline Other & $0(0)$ & $0(0)$ & $3(7.3)$ & $0(0)$ & $0(0)$ & $3(1.9)$ \\
\hline Weight (kg), mean (SD) & $69.7(13.9)$ & $68.5(15.2)$ & $72.8(14.5)$ & $67.7(13.2)$ & $71.9(10.6)$ & $70.2(13.5)$ \\
\hline BMI $\left(\mathrm{kg} / \mathrm{m}^{2}\right)$, mean (SD) & $26.1(5.4)$ & $25.1(4.9)$ & $26.6(5.7)$ & $26.1(4.7)$ & $26.9(4.2)$ & $26.2(4.9)$ \\
\hline \multicolumn{7}{|l|}{ Baseline characteristics } \\
\hline Disease duration (years), mean (SD) & $7.5(7.7)$ & $9.8(6.9)$ & $5.6(5.5)$ & $7.5(7.4)$ & $6.4(7.1)$ & $7.3(6.9)$ \\
\hline Concomitant steroids, n (\%) & $37(49.3)$ & $20(51.3)$ & $17(41.5)$ & $16(41.0)$ & $19(48.7)$ & $72(46.0)$ \\
\hline Prior biologic therapy & $4(5.3)$ & $7(17.9)$ & $1(2.4)$ & $0(0.0)$ & $0(0.0)$ & $8(5.1)$ \\
\hline RF positive, n (\%) & $65(86.7)$ & $39(100.0)$ & $39(95.1)$ & $36(92.3)$ & $34(87.2)$ & $148(93.7)$ \\
\hline ACPA positive, $n$ (\%) & $65(86.7)$ & $32(82.1)$ & $38(92.7)$ & $35(89.7)$ & $33(84.6)$ & $138(87.3)$ \\
\hline \multicolumn{7}{|l|}{ Baseline disease activity } \\
\hline DAS28-CRP, mean (SD) & $5.6(1.0)$ & $5.3(1.0)$ & $5.5(1.0)$ & $5.3(1.0)$ & $5.4(0.7)$ & $5.4(0.9)$ \\
\hline Swollen joint count, mean (SD) & $14.7(8.6)$ & $15.1(10.6)$ & $13.8(8.7)$ & $13.3(10.1)$ & $12.6(6.1)$ & $13.7(9.0)$ \\
\hline Tender joint count, mean (SD) & $24.0(12.5)$ & $21.1(12.9)$ & $23.9(12.1)$ & $25.9(12.3)$ & $21.5(10.2)$ & $23.1(11.9)$ \\
\hline Patient pain (mm), mean (SD) & $61.8(19.8)$ & $57.5(23.8)$ & $58.6(24.1)$ & $58.1(18.7)$ & $57.7(15.8)$ & $58.0(20.8)$ \\
\hline Patient global assessment of disease activity (mm), mean (SD) & $61.9(19.4)$ & $58.0(21.9)$ & $60.5(21.1)$ & $59.7(17.4)$ & $58.1(14.2)$ & $59.1(18.8)$ \\
\hline Physician global assessment of disease activity $(\mathrm{cm})$, mean (SD) & $6.3(1.3)$ & $5.2(1.9)$ & $6.1(1.6)$ & $6.3(1.6)$ & $5.7(1.4)$ & $5.8(1.7)$ \\
\hline
\end{tabular}

ACPA, anti-citrullinated protein antibody; BMI, body mass index; CRP, c-reactive protein; CV, coefficient of variation; DAS, disease activity score; ESR, erythrocyte sedimentation rate; HAQ-DI, Health Assessments Questionnaire-Disability Index; RF, rheumatoid factor; SD, standard deviation.

Within the 12-week treatment period, 26 (32.9\%) subjects receiving placebo and 73 (45.6\%) subjects receiving mavrilimumab experienced an AE.

The protocol mandated that reductions in DLCO $>20 \%$ of baseline be reported as AEs regardless of clinical significance. As such, these were the most frequently reported AEs (5 (6.3\%) placebo and 19 (11.9\%) mavrilimumab). Only two subjects (one placebo and one in the $10 \mathrm{mg}$ cohort) discontinued because of DLCO reductions; no lung toxicities were detected as assessed by an independent pulmonologist. In the 30, 50, and $100 \mathrm{mg}$ groups, there was no difference in DLCO event rate compared with placebo. Further, no clinically significant changes in serum SP-D and KL- 6 were observed over the 3 months of treatment or 3 months follow-up across treatment groups (see web only files).

There were no clinically significant or persistent changes in lung function tests performed by spirometry. Nasopharyngitis and upper respiratory tract infections (all mild-to-moderate in severity) were the next most common events. Most AEs were mild or moderate in intensity.

There were no deaths during the study, and the frequency or severity of AEs was not dependent on mavrilimumab dose.

SAEs were reported in one subject receiving placebo (worsening of RA, which resulted in discontinuation) and four subjects receiving mavrilimumab; two in the $10 \mathrm{mg}$ cohort, (intervertebral disc disorder and spontaneous abortion); and two in the $30 \mathrm{mg}$ cohort, (fracture of the humerus and fracture of the patella). None of the SAEs was considered related to the study drug.

No instances of severe hypersensitivity, anaphylaxis, or serious injection site reactions (local or systemic) were reported during the treatment period. One (2.5\%) subject in the $50 \mathrm{mg}$ cohort experienced a mild rash, which was assessed as a hypersensitivity reaction that resolved spontaneously within $10 \mathrm{~h}$.

\section{Pharmacokinetics and Immunogenicity}

Maximum serum concentration of mavrilimumab was observed approximately 3 days postdose, and PK steady-state was reached by day 57 in all dose groups. The PK exposure was more than dose-proportional. At the $100 \mathrm{mg}$ dose, the terminalphase PK half-life was $~ 13$ days.

During the study, 23 subjects developed detectable ADA (3 placebo and 20 treated). Generally, ADA titres were low and transient and did not impact the PK. High-titre ADAs were reported in 1 placebo (1.3\%) subject and 10 mavrilimumab $(6.3 \%$; 3 at $10 \mathrm{mg}, 4$ at $30 \mathrm{mg}, 1$ at $50 \mathrm{mg}$, and 2 at $100 \mathrm{mg})$ subjects. Although the presence of ADA in these subjects was associated with reduced $\mathrm{PK}$ exposure, no correlation was observed with tolerability or tachyphylaxis.

\section{DISCUSSION}

New therapeutic options capable of delivering a profound and rapid onset of action are desirable in RA because of the chronic 


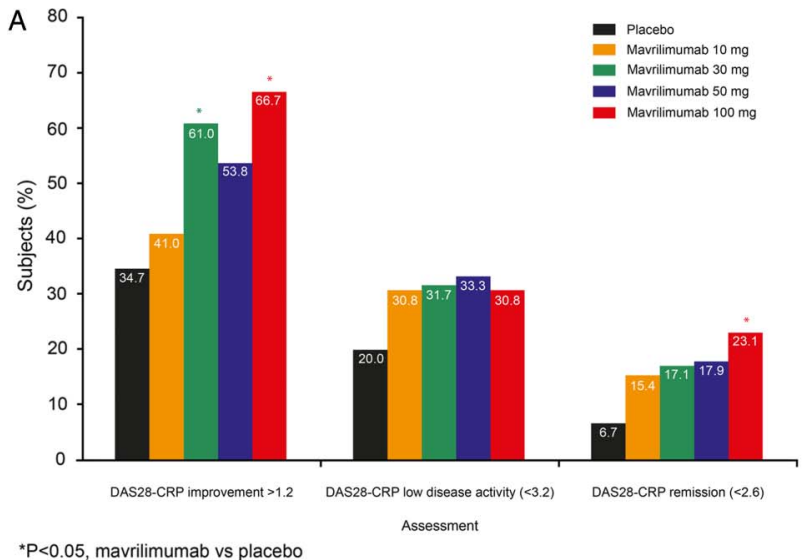

C

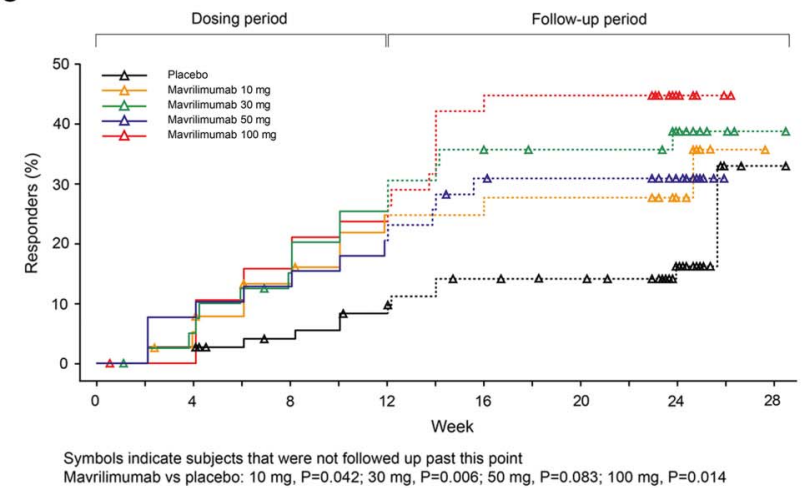

B

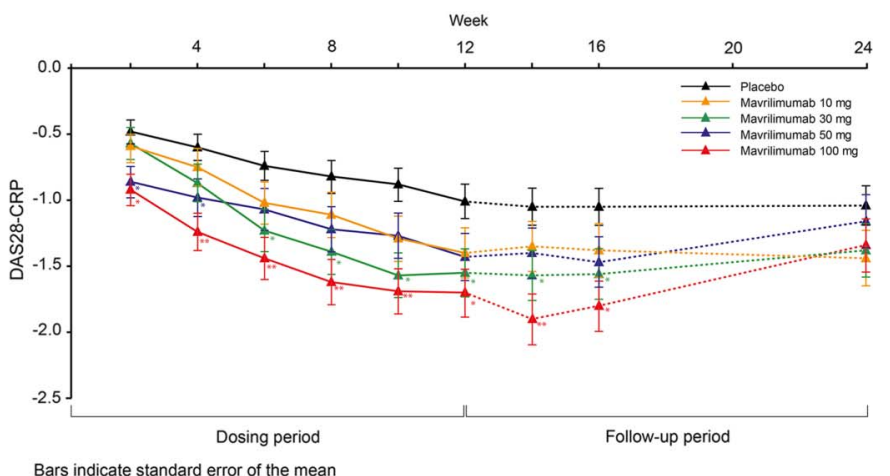

$* P<0.05 ; * * P<0.001$, mavrilimumab vs placeb

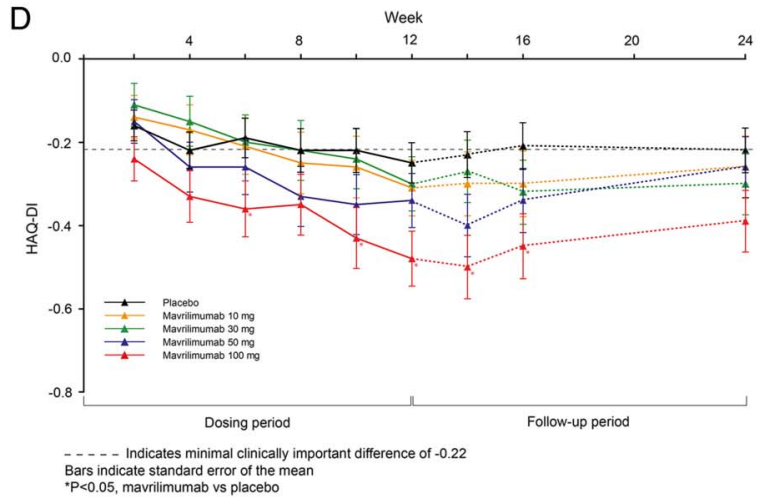

Treatment

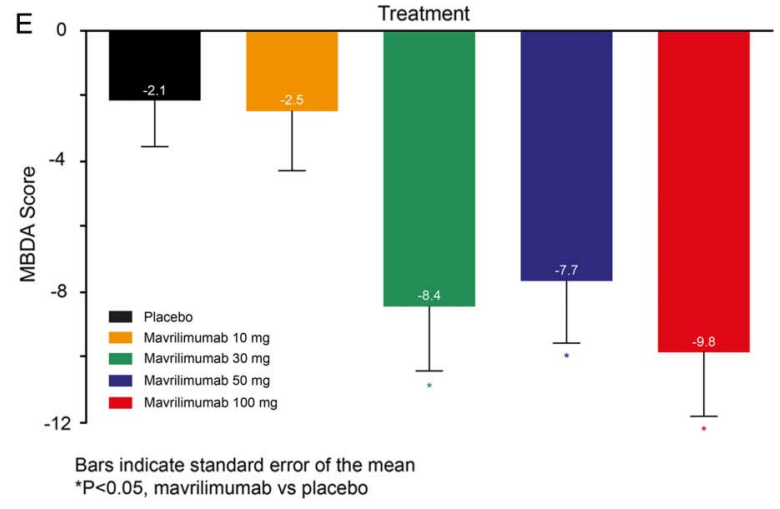

Figure 2 (A-E) Efficacy according to DAS-28 and Health Assessment Questionnaire Disability Index (HAQ-DI) assessments (ITT population).

(A) DAS28-CRP responses by treatment group at week 12. (B) Mean DAS28-CRP by visit. (C) Time to onset of DAS28-CRP <2.6. (D) Adjusted mean HAQ-DI change from baseline by visit. (E) Changes in MBDA Score from baseline seen at week 12.

progressive nature of the disease. Despite a variety of effective therapies currently available for the treatment of RA, many patients still fail to achieve clinical remission, show an inadequate response, or cannot maintain a response. ${ }^{1}$ 29-31

Our study shows that mavrilimumab, the first investigational human monoclonal antibody to target GM-CSFR $\alpha$, improves the signs and symptoms of RA in subjects with active disease despite stable methotrexate treatment. The study met its primary endpoint, and rapid and sustained improvement was demonstrated by DAS28-CRP, HAQ-DI, and ACR responses, particularly at the $100 \mathrm{mg}$ dose. Significant improvements in DAS28-CRP were seen as early as week 2 at the two highest doses (50 and $100 \mathrm{mg}$ ), and in all dose groups, scores continued to improve throughout the 12-week treatment period. After treatment was discontinued at week 12, responses were sustained for $\geq 4$ weeks; these diminished over the 12-week off-treatment period, but DAS28-CRP and ACR20 responses were maintained in the $100 \mathrm{mg}$ group throughout this follow-up period. At week 24, the treatment response was maintained for HAQ-DI, swollen and tender joint counts, but there was no difference from placebo for the physician and patient global assessments, patient pain, CRP, and ESR. Of note is the observed placebo response rate, which was higher than assumed in the sample size calculation. Despite this, the primary endpoint was met and significant improvements were observed. Moreover, the differences in baseline characteristics in the $50 \mathrm{mg}$ group were not found to account for the lower proportion of subjects achieving a $\geq 1$.2-point reduction in DAS28-CRP or ACR20 in that treatment group.

Improvements in the MBDA composite scores complement and support the dose-dependent decrease in disease activity over the 12 weeks of treatment. Suppression of individual 

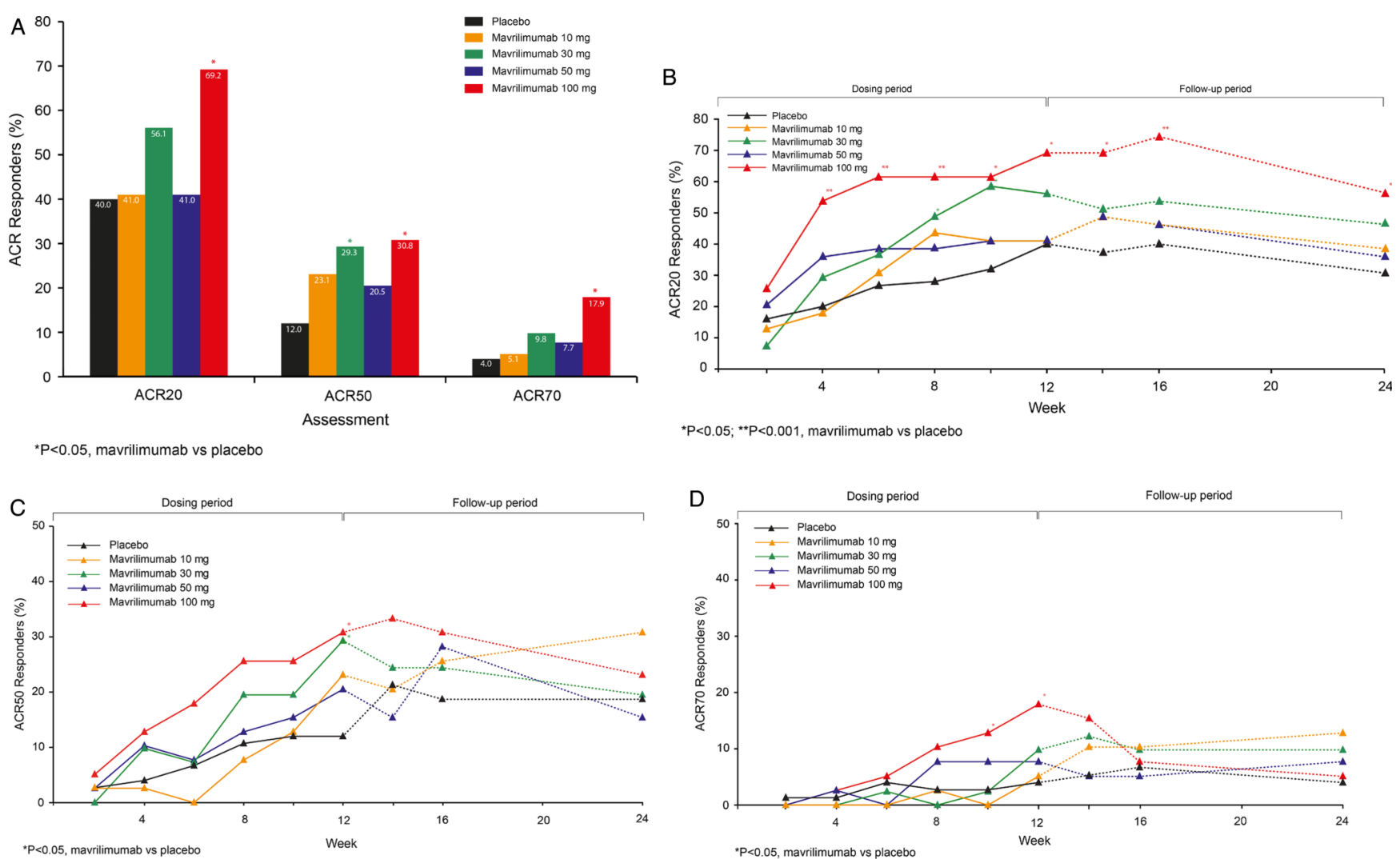

Figure 3 Efficacy according to American College of Rheumatology (ACR) assessment (ITT population). (A) ACR responses by treatment group at week 12. (B) ACR20 responses by visit. (C) ACR50 responses by visit. (D) ACR70 responses by visit.

biomarkers within the panel suggests a beneficial modulation of pathophysiological pathways associated with RA including global inflammation (CRP, IL-6, SAA) and intra-articular pathology (MMP3, YKL-40). ${ }^{32-36}$ Changes in acute phase proteins and IL- 6 occurred within 1 month, suggesting a direct effect on IL-6 production and consequently acute phase reactants. Chronic suppression of IL- 6 with mavrilimumab may result in some of the beneficial mechanisms ascribed to IL-6 therapy in RA, such as suppressing Th17 cells, either indirectly ${ }^{37}$ or directly. ${ }^{38-40}$ The direct effects of GM-CSF inhibition on MMP3 and YKL-40 has not, to our knowledge, been described previously, but may indicate a beneficial effect on cartilage degradation. Further research is required to understand the effect of mavrilimumab on MMP3 biology in circulation and the joint.

Although we only evaluated the effects of mavrilimumab over 12 weeks, it was particularly encouraging that at the highest $(100 \mathrm{mg})$ dose, $23.1 \%$ of subjects achieved DAS28-CRP $<2.6$ (placebo: $6.7 \%$ ), and $17.9 \%$ showed an ACR70 response (placebo: $4.0 \%$ ). Separation between the placebo and active groups was observed as early as week 4 for DAS28-CRP $<2.6$, suggesting a rapid onset of action even for this high-hurdle endpoint. The number of subjects achieving DAS28-CRP $<2.6$ and/or ACR70 response was still rising at 12 weeks, suggesting that peak efficacy may not have been achieved. It has been shown previously that response to some biologic treatments continues to increase over the first 24 weeks of treatment, and a significant proportion of partial responders and non-responders at week 12 may go on to achieve a clinical response with continued treatment. ${ }^{41}$

The safety profile was consistent with a previous phase 1 study of mavrilimumab in subjects with RA. ${ }^{13}$ Due to the link between GM-CSF and alveolar macrophage function and clearance of lung surfactant proteins, we carried out intensive pulmonary lung function tests as well as assays for biomarkers of lung damage such as SP-D and KL-6. At the study start, there was considerable variability in DLCO measurements, contributing to the increase in reported AEs in the $10 \mathrm{mg}$ group. With greater experience with DLCO measurements, this AE rate was not observed in the subsequent cohorts. No meaningful differences were noted for SP-D and KL- 6 between the active and placebo groups. Further, SP-D and KL-6 levels at baseline were representative of those described for healthy controls and RA patients with no interstitial lung disease. ${ }^{42-44}$ No serious or opportunistic infections or severe hypersensitivity reactions were reported in this patient population during the observation period.

The PK of mavrilimumab ${ }^{14}$ was nonlinear with dose due to GM-CSFR-mediated clearance. One placebo (1.3\%) and 10 mavrilimumab-treated subjects (6.3\%) developed ADA with a titre $\geq 4$. Most incidences of ADA occurred in the lower dose groups (10 and $30 \mathrm{mg}$ ). Although these instances were associated with somewhat reduced PK exposure; there was no apparent correlation between $\mathrm{ADA}$ and hypersensitivities or reduced clinical responses. Longer-term studies will be necessary to understand the potential for mavrilimumab ADAs to affect the safety and/or efficacy profile of the molecule.

There are some important limitations to our study. It was a short-term, early phase study with a relatively small number of subjects in each treatment group. Because of potential safety concerns, doses were escalated sequentially, rather than by adopting the standard parallel-group design.

Despite these limitations, our study suggests that targeting the alpha subunit of the GM-CSFR may be a novel approach to RA treatment. Mavrilimumab, especially at the higher doses, appears to produce rapid and clinically meaningful effects 
Table 2 Most frequent treatment-emergent AEs and most frequent treatment-related AEs ( $>1$ subject in placebo or total mavrilimumab groups) (safety population)

\begin{tabular}{|c|c|c|c|c|c|c|}
\hline \multirow[b]{2}{*}{$A E, n(\%)$} & \multirow[b]{2}{*}{ Placebo $(n=79)$} & \multicolumn{5}{|l|}{ Mavrilimumab } \\
\hline & & $10 \mathrm{mg}(\mathrm{n}=39)$ & $30 \mathrm{mg}(\mathrm{n}=41)$ & $50 \mathrm{mg}(\mathrm{n}=40)$ & $100 \mathrm{mg}(\mathrm{n}=40)$ & Total $(n=160)$ \\
\hline Total number of AEs & 74 & 39 & 40 & 37 & 29 & 145 \\
\hline Total subjects reporting $\geq 1 \mathrm{AE}$ & $36(45.6)$ & $25(64.1)$ & $24(58.5)$ & $19(47.5)$ & $23(57.5)$ & $91(56.9)$ \\
\hline Carbon monoxide diffusing capacity decreased & $5(6.3)$ & $10(25.6)$ & $3(7.3)$ & $3(7.5)$ & $3(7.5)$ & $19(11.9)$ \\
\hline Nasopharyngitis & $2(2.5)$ & $1(2.6)$ & $4(9.8)$ & $1(2.5)$ & $4(10.0)$ & $10(6.3)$ \\
\hline Upper respiratory tract infection & $4(5.1)$ & $2(5.1)$ & $1(2.4)$ & $1(2.5)$ & $2(5.0)$ & $6(3.8)$ \\
\hline Worsening of rheumatoid arthritis & $2(2.5)$ & $2(5.1)$ & $1(2.4)$ & $2(5.0)$ & $0(0)$ & $5(3.1)$ \\
\hline Transaminases increased & $0(0)$ & $1(2.6)$ & $1(2.4)$ & $1(2.5)$ & $1(2.5)$ & $4(2.5)$ \\
\hline Alanine aminotransferase increased & $0(0)$ & $0(0)$ & $2(4.9)$ & $1(2.5)$ & $1(2.5)$ & $4(2.5)$ \\
\hline Pharyngitis & $0(0)$ & $0(0)$ & $1(2.4)$ & $2(5.0)$ & $1(2.5)$ & $4(2.5)$ \\
\hline Oral herpes & $0(0)$ & $1(2.6)$ & $2(4.9)$ & $0(0)$ & $0(0)$ & $3(1.9)$ \\
\hline Hypercholesterolemia & $1(1.3)$ & $1(2.6)$ & $1(2.4)$ & $1(2.5)$ & $0(0)$ & $3(1.9)$ \\
\hline Neutropenia & $0(0)$ & $0(0)$ & $2(4.9)$ & $1(2.5)$ & $0(0)$ & $3(1.9)$ \\
\hline Influenza & $1(1.3)$ & $1(2.6)$ & $0(0)$ & $2(5.0)$ & $0(0)$ & $3(1.9)$ \\
\hline Hepatic enzyme increased & $2(2.5)$ & $1(2.6)$ & $0(0)$ & $0(0)$ & $1(2.5)$ & $2(1.3)$ \\
\hline Injection site pain & $0(0)$ & $0(0)$ & $1(2.4)$ & $0(0)$ & $1(2.5)$ & $2(1.3)$ \\
\hline Anemia & $4(5.1)$ & $1(2.6)$ & $0(0)$ & $0(0)$ & $1(2.5)$ & $2(1.3)$ \\
\hline Bronchitis & $1(1.3)$ & $0(0)$ & $0(0)$ & $0(0)$ & $2(5.0)$ & $2(1.3)$ \\
\hline Amenorrhea & $0(0)$ & $1(2.6)$ & $0(0)$ & $0(0)$ & $1(2.5)$ & $2(1.3)$ \\
\hline Skin exfoliation & $0(0)$ & $1(2.6)$ & $0(0)$ & $1(2.5)$ & $0(0)$ & $2(1.3)$ \\
\hline Monocytopenia & $2(2.5)$ & $0(0)$ & $0(0)$ & $0(0)$ & $1(2.5)$ & $1(0.6)$ \\
\hline Hypertension & $2(2.5)$ & $0(0)$ & $1(2.4)$ & $0(0)$ & $0(0)$ & $1(0.6)$ \\
\hline Rash & $2(2.5)$ & $0(0)$ & $1(2.4)$ & $0(0)$ & $0(0)$ & $1(0.6)$ \\
\hline Cough & $2(2.5)$ & $0(0)$ & $0(0)$ & $0(0)$ & $0(0)$ & $0(0)$ \\
\hline \multicolumn{7}{|l|}{ Treatment-related adverse events } \\
\hline Total subjects reporting $\geq 1$ related $A E$ & $11(13.9)$ & $8(20.5)$ & $9(22.0)$ & $8(20.0)$ & $7(17.5)$ & $32(20.0)$ \\
\hline Carbon monoxide diffusing capacity decreased & $1(1.3)$ & $4(10.3)$ & $2(4.9)$ & $1(2.5)$ & $0(0)$ & $7(4.4)$ \\
\hline Upper respiratory tract infection & $1(1.3)$ & $0(0)$ & $0(0)$ & $1(2.5)$ & $2(5.0)$ & $3(1.9)$ \\
\hline Neutropenia & $0(0)$ & $0(0)$ & $2(4.9)$ & $1(2.5)$ & $0(0)$ & $3(1.9)$ \\
\hline Worsening of rheumatoid arthritis & $0(0)$ & $0(0)$ & $1(2.4)$ & $1(2.5)$ & $0(0)$ & $2(1.3)$ \\
\hline Transaminases increased & $0(0)$ & $0(0)$ & $0(0)$ & $1(2.5)$ & $1(2.5)$ & $2(1.3)$ \\
\hline Hepatic enzyme increased & $2(2.5)$ & $1(2.6)$ & $0(0)$ & $1(2.5)$ & $0(0)$ & $1(0.6)$ \\
\hline \multicolumn{7}{|l|}{ Serious adverse events } \\
\hline Total subjects reporting $\geq 1$ related $\mathrm{SAE}$ & 1 & 2 & 2 & 0 & 0 & 0 \\
\hline
\end{tabular}

$\mathrm{AE}$, adverse event; $\mathrm{SAE}$, serious adverse event.

across a number of disease activity parameters with no unexpected safety concerns. This hypothesis will be evaluated in future larger, appropriately powered clinical studies.

\section{Author affiliations}

${ }^{1}$ Charité- University Medicine Berlin, Department of Rheumatology and Clinical Immunology Free University and Humboldt University, Berlin, Germany

${ }^{2}$ Division of Rheumatology, Immunology and Allergy Brigham and Women's Hospital, Boston, Massachusetts, USA

${ }^{3}$ Glasgow Biomedical Research Centre, Glasgow, UK

${ }^{4}$ Department of Rheumatology, Gartnavel General Hospital, Glasgow, UK

${ }^{5} \mathrm{SIH}$ Kemerovo Regional Clinical Hospital, Kemerovo, Russian Federation

${ }^{6}$ Donetsk National Medical University named after M. Gorky, Donestsk, Ukraine

7óbudai Egészségügyi Centrum, Budapest, Hungary

${ }^{8}$ Medlmmune Ltd, Cambridge, UK

${ }^{9}$ Medlmmune, LLC, Gaithersburg, Maryland, USA

${ }^{10}$ Crescendo Bioscience Inc., South San Francisco, California, USA

${ }^{11}$ Medlmmune, LLC, Hayward, California, USA

${ }^{12}$ Imperial College, Division of Medicine, Immunology/Inflammation, London, UK

${ }^{13}$ Lilly Biotechnology Center, San Diego, California, USA

${ }^{14}$ Kaggle, San Francisco, Califorinia, USA

${ }^{15}$ US Army Medical Research Institute of Infectious Diseases, Fort Detrick, MD, USA

Acknowledgements The authors wish to acknowledge Geraldine Grove, Didier Saurigny, Bente Larson, and Mark Hopton for their support in the conduct and interpretation of the study. Editorial assistance was provided by Eleanor Steele, BSc, from OXV Communications, Macclesfield, UK. The authors thank Ruth Pereira, $\mathrm{PhD}$, for her critical review of the manuscript and her valuable comments.
The authors would like to thank the following EARTH study investigators for their valuable contribution to the study: Bulgaria: Anastas Batalov, Ivan Goranov, Vladimir Kadinov, Rumen Stoilov, Daniela Yaneva; Czech Republic: Jiri Vencovsky, Ladislav Bortlik, Petr Vitek, Dagmar Galatikova, Zuzana Urbanova, Zuzana Stejfova; Estonia: Eevi Parsik, Jaak Talli, Ivo Valter; Hungary: Ildiko Kiss, Janos Bartalos, Istvan Szombati, Marianne Szongoth; Latvia: Helena Mikazane, Samite Saleniece, Daina Saulite-Kandevica; Lithuania: Sigitas Stonkus, Algirdas Venalis; Poland: Dariusz Chudzik, Stefan Daniluk, Przemyslaw Kotyla, Iwona Swierzewska-Olech, Leszek Szczepanski, Malgorzata Szymanska, Piotr Leszczynski, Wlodzimierz Samborski, Maria Stopinska- Polaszewska, Grazyna Krzyzanowska; Romania: Florin Radulescu, Marian Sandu; Russia: Olga Ershova, Anna Galustyan, Alexander Gordienko, Nikolay Korshunov, Galina Matsievskaia, Ildar Salikhov, Valeriy Shirinskiy, Elena Zonova, Olga Barbarash, Galina Chumakova, Andrey Dorokhov; Ukraine: Kateryna Amosova, Oleksandr Dyadyk, Mykola Vatutin, Volodymyr Kovalenko, Vladislav Povoroznyuk, Semen Ter-Vartanyan, Grigoriy Ignatenko

Funding The study was sponsored by Medlmmune Ltd.

Competing interests Gerd Burmester is a consultant for Medlmmune, Abbott, BMS, MSD, Pfizer, Roche, and UCB; has received travel reimbursement for meetings for the study from Medlmmune; and has grants from and is a speaker for Abbott, BMS, MSD, Pfizer, Roche, and UCB. Michael Weinblatt is a consultant for Abbott, Amgen, Astellas, AstraZeneca, Biogen/ldec, BMS, Crescendo Biosciences, Hoffman La Roche, Janssen (Centocor), Lilly, Medlmmune, Merck, Pfizer, UCB, and Vertex. He has received funding for travel expenses to attend consulting meetings for the companies listed above and has grants from Biogen/ldec, Crescendo Bioscience, and Medlmmune. lain Mclnnes is a consultant for Medlmmune, AstraZeneca, Boehringer Ingelheim, Crescendo Bioscience, Johnson \& Johnson, NovoNordisk, Pfizer, Roche, and UCB has grants from AstraZeneca, BMS, MSD, Pfizer, Roche, UCB; and is a speaker for BMS, MSD, Pfizer, Roche, and UCB. Duncan Porter has received fees for 
participation in the Mavrilimumab Development Advisory Board; is a consultant for BMS, Pfizer, and Roche; has grants from Pfizer and Roche; is a speaker for Abbott; and has received travel reimbursement from Abbott, BMS, Roche, and UCB. Olga Barbarash, Mykola Vatutin, and Istvan Szombati have nothing to disclose. Guy Cavet is an employee of and has stock options from Crescendo Bioscience. Ehsanollah Esfandieri, Chris Kane, and Fabio Magrini were employees of Medlmmune while the study was being conducted; Fabio Magrini owned stock in AstraZeneca. Matt Sleeman and Alex Godwood are employees of Medlmmune and own stock in AstraZeneca. Bing Wang is an employee of Medlmmune.

Provenance and peer review Not commissioned; externally peer reviewed.

Open Access This is an Open Access article distributed in accordance with the Creative Commons Attribution Non Commercial (CC BY-NC 3.0) license, which permit others to distribute, remix, adapt, build upon this work non-commercially, and license their derivative works on different terms, provided the original work is properly cited and the use is non-commercial. See: http://creativecommons.org/licenses/by-nc/3.0/

\section{REFERENCES}

1. Campbell J, Lowe D, Sleeman MA. Developing the next generation of monoclonal antibodies for the treatment of rheumatoid arthritis. $\mathrm{Br} \mathrm{J}$ Pharmacol 2011;162:1470-84

2. Cornish AL, Campbell IK, McKenzie BS, et al. G-CSF and GM-CSF as therapeutic targets in rheumatoid arthritis. Nat Rev Rheumatol 2009;5:554-9.

3. Mulherin D, Fitzgerald 0, Bresnihan B. Synovial tissue macrophage populations and articular damage in rheumatoid arthritis. Arthritis Rheum 1996;39:115-24.

4. Bresnihan B, Gerlag DM, Rooney T, et al. Synovial macrophages as a biomarker of response to therapeutic intervention in rheumatoid arthritis: standardization and consistency across centers. J Rheumatol 2007;34:620-2.

5. de Hair MJ, Harty LC, Gerlag DM, et al. Synovial tissue analysis for the discovery of diagnostic and prognostic biomarkers in patients with early arthritis. $J$ Rheumatol 2011:38:2068-72.

6. Haringman JJ, Gerlag DM, Zwinderman AH, et al Synovial tissue macrophages: a sensitive biomarker for response to treatment in patients with rheumatoid arthritis. Ann Rheum Dis 2005;64:834-8.

7. Bell AL, Magill MK, McKane WR, et al. Measurement of colony-stimulating factors in synovial fluid: potential clinical value. Rheumatol Int 1995;14:177-82.

8. Fiehn C, Wermann M, Pezzutto A, et al. (Plasma GM-CSF concentrations in rheumatoid arthritis, systemic lupus erythematosus and spondyloarthropathy). Z Rheumatol 1992;51:121-6.

9. Davis JM III, Knutson KL, Strausbauch MA, et al. Analysis of complex biomarkers for human immune-mediated disorders based on cytokine responsiveness of peripheral blood cells. J Immunol 2010:184:7297-304.

10. Hazenberg BP, Van Leeuwen MA, Van Rijswijk MH, et al. Correction of granulocytopenia in Felty's syndrome by granulocyte-macrophage colony-stimulating factor. Simultaneous induction of interleukin-6 release and flare-up of the arthritis. Blood 1989:74:2769-70.

11. Pereira J, Velloso ED, Loterio HA, et al. Long-term remission of neutropenia in Felty's syndrome after a short GM-CSF treatment. Acta Haematol 1994;92:154-6.

12. de Vries EG, Willemse PH, Biesma B, et al. Flare-up of rheumatoid arthritis during GM-CSF treatment after chemotherapy. Lancet 1991:338:517-18.

13. Burmester GR, Feist E, Sleeman MA, et al. Mavilimumab, a human monoclonal antibody targeting GM-CSF receptor-\{alpha\}, in subjects with rheumatoid arthritis: a randomised, double-blind, placebo-controlled, phase I, first-in-human study. Ann Rheum Dis 2011;70:1542-9.

14. Wang B, Lau YY, Liang M, et al. Mechanistic modeling of antigen sink effect for mavrilimumab following intravenous administration in patients with rheumatoid arthritis. J Clin Pharmacol 2011:52:1150-61.

15. Smolen JS, Breedveld FC, Schiff MH, et al. A simplified disease activity index for rheumatoid arthritis for use in clinical practice. Rheumatology (Oxford) 2003:42:244-57.

16. Arnett FC, Edworthy SM, Bloch DA, et al. The American Rheumatism Association 1987 revised criteria for the classification of rheumatoid arthritis. Arthritis Rheum 1988:31:315-24.

17. Wells G, Becker JC, Teng J, et al. Validation of the 28-joint Disease Activity Score (DAS28) and European League Against Rheumatism response criteria based on C-reactive protein against disease progression in patients with rheumatoid arthritis, and comparison with the DAS28 based on erythrocyte sedimentation rate. Ann Rheum Dis 2009;68:954-60.

18. Fries JF, Spitz $P$, Kraines RG, et al. Measurement of patient outcome in arthritis. Arthritis Rheum 1980;23:137-45.

19. Bakker MF, Cavet G, Jacobs JW, et al. Performance of a multi-biomarker score measuring rheumatoid arthritis disease activity in the CAMERA tight control study. Ann Rheum Dis 2012;71:1692-7.

20. Curtis JR, van der Helm-van Mil AH, Knevel R, et al. Validation of a novel multi-biomarker test to assess rheumatoid arthritis disease activity. Arthritis Care Res 2012: (accessed 6 Nov 2012). accepted article.
21. Crescendo Bioscience I. Vectra DA disease activity test. 2012. http://www. vectra-da.com/ (accessed 12 Apr 2012)

22. Kitamura T, Tanaka N, Watanabe J, et al. Idiopathic pulmonary alveolar proteinosis as an autoimmune disease with neutralizing antibody against granulocyte/macrophage colony-stimulating factor. J Exp Med 1999;190 875-80.

23. Trapnell BC, Carey BC, Uchida K, et al. Pulmonary alveolar proteinosis, a primary immunodeficiency of impaired GM-CSF stimulation of macrophages. Curr Opin Immunol 2009;21:514-21.

24. Suzuki T, Sakagami T, Rubin BK, et al. Familial pulmonary alveolar proteinosis caused by mutations in CSF2RA. J Exp Med 2008;205:2703-10.

25. Seymour JF, Presneill JJ. Pulmonary alveolar proteinosis: progress in the first 44 years. Am J Respir Crit Care Med 2002;166:215-35.

26. Seymour JF, Doyle IR, Nakata K, et al. Relationship of anti-GM-CSF antibody concentration, surfactant protein A and B levels, and serum LDH to pulmonary parameters and response to GM-CSF therapy in patients with idiopathic alveolar proteinosis. Thorax 2003;58:252-7.

27. Inoue $\mathbf{Y}$, Trapnell BC, Tazawa $\mathrm{R}$, et al. Characteristics of a large cohort of patients with autoimmune pulmonary alveolar proteinosis in Japan. Am J Respir Crit Care Med 2008;177:752-62

28. Benjamini $\mathbf{Y}$, Hochberg $Y$. Controlling the false discovery rate: a practical and powerful approach to multiple testing. J Roy Statist Soc Ser B (Methodological) 1995:57:289-300.

29. Goekoop-Ruiterman YP, de Vries-Bouwstra JK, Allaart CF, et al. Clinical and radiographic outcomes of four different treatment strategies in patients with early rheumatoid arthritis (the BeSt study): a randomized, controlled trial. Arthritis Rheum 2005; 52:3381-90.

30. Breedveld FC, Weisman MH, Kavanaugh AF, et al. The PREMIER study: A multicenter, randomized, double-blind clinical trial of combination therapy with adalimumab plus methotrexate versus methotrexate alone or adalimumab alone in patients with early, aggressive rheumatoid arthritis who had not had previous methotrexate treatment. Arthritis Rheum 2006:54:26-37.

31. St Clair EW, van der Heijde DM, Smolen JS, et al. Combination of infliximab and methotrexate therapy for early rheumatoid arthritis: a randomized, controlled trial. Arthritis Rheum 2004;50:3432-43.

32. McInnes IB, Schett G. The pathogenesis of rheumatoid arthritis. N Engl J Med 2011;365:2205-19.

33. Mease PJ. The potential roles for novel biomarkers in rheumatoid arthritis assessment. Clin Exp Rheumatol 2011;29:567-74.

34. Johansen JS, Stoltenberg M, Hansen M, et al. Serum YKL-40 concentrations in patients with rheumatoid arthritis: relation to disease activity. Rheumatology (Oxford) 1999;38:618-26.

35. Recklies AD, White $\mathrm{C}$, Ling $\mathrm{H}$. The chitinase 3 -like protein human cartilage glycoprotein 39 (HC-gp39) stimulates proliferation of human connective-tissue cells and activates both extracellular signal-regulated kinase- and protein kinase B-mediated signalling pathways. Biochem J 2002;365(Pt 1):119-26.

36. Knudsen LS, Klarlund M, Skjodt $\mathrm{H}$, et al. Biomarkers of inflammation in patients with unclassified polyarthritis and early rheumatoid arthritis. Relationship to disease activity and radiographic outcome. J Rheumatol 2008;35:1277-87.

37. Tanaka T, Narazaki M, Kishimoto T. Therapeutic targeting of the interleukin-6 receptor. Annu Rev Pharmacol Toxicol 2012:52:199-219.

38. Sonderegger $\mathbf{I}$, lezzi G, Maier R, et al. GM-CSF mediates autoimmunity by enhancing IL-6-dependent Th17 cell development and survival. J Exp Med 2008;205:2281-94

39. El-Behi M, Ciric B, Dai H, et al. The encephalitogenicity of $T(H) 17$ cells is dependent on IL-1- and IL-23-induced production of the cytokine GM-CSF. Nat Immunol 2011:12:568-75.

40. Codarri L, Gyulveszi G, Tosevski V, et al. RORgammat drives production of the cytokine GM-CSF in helper T cells, which is essential for the effector phase of autoimmune neuroinflammation. Nat Immunol 2011;12:560-7.

41. Kavanaugh A, Klareskog L, van der Heijde D, et al. Improvements in clinical response between 12 and 24 weeks in patients with rheumatoid arthritis on etanercept therapy with or without methotrexate. Ann Rheum Dis 2008:67:1444-7.

42. Miyata M, Sakuma F, Fukaya E, et al. Detection and monitoring of methotrexate-associated lung injury using serum markers KL-6 and SP-D in rheumatoid arthritis. Intern Med 2002;41:467-73.

43. Ohnishi H, Yokoyama A, Kondo K, et al. Comparative study of KL-6, surfactant protein-A, surfactant protein-D, and monocyte chemoattractant protein-1 as serum markers for interstitial lung diseases. Am J Respir Crit Care Med 2002:165:378-81.

44. Oyama T, Kohno N, Yokoyama A, et al. Detection of interstitial pneumonitis in patients with rheumatoid arthritis by measuring circulating levels of KL-6, a human MUC1 mucin. Lung 1997;175:379-85 